\title{
KUNCI WASIAT KEBUDAYAAN: MEMBUKA PERADABAN DENGAN AKSARA BALI ${ }^{1}$
}

\author{
I Wayan Suardiana ${ }^{2}$ \\ e-mail: i.suardiana@yahoo.co.id
}

\begin{abstract}
"Djadilah pewahju rakjat! Fakultas Udajana harus menggali masa lampau kita jang gilang-gemilang kini jang penuh perdjuangan dan masa datang jang tjemerlang!”

(Bung Karno)

"Bagi Pulau Bali jang telah terkenal sebagai peti tempat penjimpanan sastra dan budaja lama, maka berdirinya Fakultas Sastra ini boleh kita anggap sebagai kuntji wasiat untuk membuka perbendaharaan itu setjara ilmiah!"

(Prof. Dr. Peorbatjaraka)
\end{abstract}

\begin{abstract}
Abstrak
Pendirian Fakultas Sastra Udayana (sekarang bernama Fakultas Ilmu Budaya, Universitas Udayana) oleh Bung Karno tahun 1958 silam memiliki tujuan mulia, yakni menyelamatkan warisan leluhur orang Bali yang tersurat di dalam daun lontar. Amanat ini telah ditangkap dengan baik oleh Peorbatjaraka, sebagai akhli Jawa Kuna dengan mengatakan dalam pidatonya, “...pendirian Fakultas Sastra Udayana agar mampu sebagai kunci wasiat untuk membuka peti penyimpanan sastra dan budaya secara ilmiah". Artikel ini menelisik harapan dari dua tokoh pendiri Fakultas Ilmu Budaya yang sudah berlangsung enam puluhan tahun itu apakah saat ini sudah dilaksanakan oleh pemangku kepentingan di tanah Bali ini. Data yang diolah merupakan data kualitatif yang didapat melalui metode studi pustaka. Data disajikan dengan metode deskriptif analitis dibantu teknik deduktif-induktif. Berdasarkan analisa bahwa pesan dari kedua tokoh tersebut (terutama kurun1970-an sampai dengan tahun 2000-an awal) dalam hal menyelamatkan warisan leluhur Bali dalam bentuk lontar kurang membanggakan. Hal ini akibat terjadi stagnasi dalam hal pemanfaatan aksara Bali sebagai akar penyingkap kebudayaan Bali. Titik cerah mulai tampak tahun 2018 dengan dikeluarkannya Perda nomor 1 tahun 2018 tentang Bahasa, Aksara, dan Sastra Bali dan diperkuat oleh Pergub Bali Nomor 80 Tahun 2018 tentang Pelindungan dan Penggunaan Bahasa, Aksara, dan Sastra Bali serta Penyelenggaraan Bulan Bahasa Bali.
\end{abstract}

Kata kunci: Aksara, peradaban, kebudayaan Bali.

\section{Pendahuluan}

Enam puluh satu tahun silam, tepatnya 29 September 1958 Presiden pertama Republik Indonesia, Bung Karno meresmikan berdirinya Fakultas Sastra Udayana yang menjadi cikal bakal FIB dan Unud. Pada pidato pembukaan tersebut, dua tokoh penting memberikan pandangannya yang sering dikutip, namun implementasi dari pidato tersebut belum pernah diaktualisasikan. Seperti telah penulis kutip di atas, pesan tersebut mengisyaratkan pentingnya didirikan perguruan tinggi di Pulau Dewata ini. Pertama, karena Bali sebagai bagian dari Negara Kesatuan Republik Indonesia (NKRI) mempunyai Sumber Daya Manusia (SDM) unggul yang penting untuk diberikan kesempatan dalam menimba ilmu sejajar dengan saudara-saudaranya di lain pulau, terutama Pulau Jawa. Kedua, keunggulan SDM Bali yang mampu menyelamatkan warisan leluhur masyarakat Jawa, yaitu berupa naskah lontar (Lih.Teeuw. 1983: 87; Zoetmulder, 1985: 47). Dan, yang ketiga berupa warisan budaya tulis yang tersurat dengan huruf Bali di atas daun lontar.

Usia lima puluh delapan tahun, bila diandaikan sebagai manusia tentu sudah matang dalam melakoni kehidupan. Dalam konteks harapan sebagaimana tersurat dalam cuplikan pidato di atas, lantas apa kematangan yang sudah mampu ditunjukkan oleh kita di Fakultas Ilmu Budaya dan Program-program studi yang terkait yang ada di dalamnya? Inilah akan menjadi pusat perhatian kita saat diskusi nantinya dan sekaligus menjadi titik fokus dalam pembahasan selanjutnya.

\footnotetext{
${ }^{1}$ Artikel ini pernah disajikan dalam Seminar Bulanan Seri Sastra dan Budaya, Fakultas Ilmu Budaya, Universitas Udayana yang diselenggarakan pada hari Jumat, 23 Desember 2016 di Aula FIB Unud. Wujudnya seperti saat ini, telah mengalami tambahan sesuai perkembangan yang ada kurun 2016 s.d. 2019.

${ }^{2}$ Dosen Program Studi Sastra Bali, FIB Unud.
} 
Setelah dua tulisan penulis di Majalah Wahana, yakni: (1) "Merumuskan Ajeg Bali Berdasarkan Teks" edisi No. 67 TH.XXV November 2009 dan (2) "Peran Fakultas Sastra dan Budaya Universitas Udayana dalam Memaknai Pola Ilmiah Pokok (PIP) Kebudayaan Bagi UNUD" edisi No.93 TH.XXXI Nopember 2015 maka pihak Universitas yang diprakarsai oleh PR IV (sekarang WR IV) Unud lewat Pusat Kajian Bali mempercayakan kepada penulis untuk menulis paper tentang pustaka-pustaka lontar yang gayut dengan Pola Ilmiah Pokok (PIP) Kebudayaan masing-masing fakultas/prodi yang ada di lingkungan Universitas Udayana. Paper tersebut penulis sajikan dalam rangka BKFS dan Dies Natalis Universitas Udayana yang ke-54 yang mengadakan Diskusi Kelompok Terarah (FGD) di Aula Gedung Prof. Dr. Ida Bagus Mantra, Fakultas Ilmu Budaya Universitas Udayana, Rabu, 14 September 2016 dengan tema: "Peran Pustaka Lontar dalam Menunjang Pola Ilmiah Pokok (PIP) Kebudayaan Universitas Udayana."

Pola Ilmiah Pokok (PIP) "Kebudayaan" bagi Universitas Udayana pertama kali ditetapkan dalam Rapat Senat Unud tanggal 12 Maret 1976. Dari hasil rapat Senat tersebut, tahun 1983 berhasil disusun buku Statuta Unud untuk menguatkan posisi PIP dimaksud. Setelah lima tahun kemudian (1988), sebagai implementasi PIP Kebudayaan disusun buku Pedoman Pola Ilmiah Pokok yang memuat daftar beberapa matakuliah yang dianggap dapat merepresentasikan kebudayaan. Dua tahun kemudian (1990) ditulis Buku Pedoman Penerapan PIP Kebudayaan Unud. Selanjutnya, setelah 25 tahun sejak ditulisnya pedoman penerapan PIP tersebut, tidak muncul lagi buku yang memuat tentang penguatan terhadap PIP Kebudayaan bagi Unud. Meskipun Buku Statuta Unud sebagai salah satu payung hukum dalam menjalankan roda akademik di Unud telah berulang diperbaharui (terakhir menurut arsip penulis terbit Statuta Unud tahun 2007), namun PIP Kebudayaan bagi Unud tidak pernah diimplementasikan oleh masing-masing fakultas secara baik. Menurut I Made Jiwa Atmaja menyebutnya dengan istilah "Masih Mencari Landasan Konseptual" (2014: 4-7). Padahal, menurut hemat penulis, misi Unud menuju "World Class University"(Bali Post, 6 Oktober 2009), ada pada PIP Kebudayaan tersebut! Bali (Udayana ada di dalamnya) tidak punya sumber alam yang memadai, hanya punya budaya. Oleh karena demikian, pentingnya menggali budaya di masing-masing bidang keilmuan (Baca: fakultas) di Unud untuk diangkat sebagai tiang penyangga PIP Universitas mendesak untuk dilakukan!

Tulisan tentang Pola Ilmiah Pokok (PIP) Kebudayaan bagi Universitas Udayana pernah dihimpun pada Majalah Widya Pustaka Edisi Khusus Tahun VI edisi Oktober 1988 dengan Tema "Melangkah Menuju Masa Depan Mencanggihkan Kunci Wasiat untuk Menjawab Tantangan Sejarah". Buah pemikiran almarhum Prof. Dr. I Gusti Ngurah Bagus tentang seputar kebudayaan telah dibahas secara seksama yang pada intinya telah memberikan filosofis pada tataran ontologis dan epistemologi, untuk kemudian melakukan tindakan nyata lewat PIP Kebudayaan itu dalam tataran aksiologis.

Persoalannya sekarang yang juga akan menjadi pembahasan selanjutnya adalah landasan dalam tataran "AKSIOLOGIS" untuk mengimplementasikan PIP Kebudayaan bagi Unud tersebut tidak pernah terwujud. Sehingga, harapan Prof. Dr. I Gusti Ngurah Bagus "Mencanggihkan Kunci Wasiat untuk Menjawab Tantangan Sejarah" bagi Unud, merupakan tugas kita sebagai generasi selanjutnya untuk mewujudkannya! Unud akan mampu mensejajarkan predikatnya dengan universitas ternama di tingkat nasional bahkan global jika mampu menerapkan PIP Kebudayaan secara baik di masing-masing fakultas!

Bila dicermati PIP Kebudayaan tersebut telah dicetuskan sejak 12 Maret 1976. Artinya, sampai saat ini (Desember 2016) genap berusia empat puluh (40) tahun, usia yang sudah dewasa dan mestinya penerapan PIP Kebudayaan di masing-masing fakultas yang ada di lingkungan Universitas Udayana telah merata dan membumi sebagai mata kuliah unggulan prodi/fakultas. Kenyataannya, penerapan PIP Kebudayaan bagi Unud masih ada kegamangan di beberapa prodi/fakultas!

\section{Menjauhkan Akar dari Pohonnya}

Sebelum sampai pada inti persoalan yang ingin dibahas dalam tulisan singkat ini menarik disimak tentang sambutan insan kampus dan intelektual Bali tentang pemaknaan dari pidato di atas dalam konteks penyelamatan akar budaya Bali selama ini dan ke depannya. Pidato Prof. Dr. Peorbatjaraka yang menekankan: "Bagi Pulau Bali jang telah terkenal sebagai peti tempat 
penjimpanan sastra dan budaja lama, maka berdirinya Fakultas Sastra ini boleh kita anggap sebagai kuntji wasiat untuk membuka perbendaharaan itu setjara ilmiah!" selama ini salah pemaknaan bagi insan akademisi, cendekiawan Bali, dan penentu kebijakan di bidang pendidikan di Bali. Hal ini, terutama berlaku di dunia pendidikan, mengingat pelajaran bahasa Bali hanya diberikan dua jam seminggu ditambah pemakaian aksara Bali dalam buku ajar dan buku-buku penunjang lainnya tidak memadai.

Bila kita fisualisasikan kebudayaan Bali itu seperti pohon maka aksara adalah akarnya, bahasa adalah batang dari pohon tersebut, daun dan rantingnya merupakan karya sastra, kemudian bunga dan buahnya adalah kesenian. Selama ini kebudayaan Bali lebih memperhatikan kesenian (tari, tabuh, pahat, lukis) tanpa banyak menyentuh akarnya, yakni aksara. Bahkan, pembelajaran aksara Bali (termasuk bahasanya) tahun 1970-an sampai tahun 1990-an hanya sampai kelas dua Sekolah Pendidikan Menengah (SMP).

Keberadaan aksara Bali semakin terpuruk ketika teks-teks beraksara Bali dengan bahasa Jawa Kuna ditranskripsikan ke dalam huruf Latin dan diterjemahkan ke dalam bahasa Bali dan bahasa Indonesia. Terbitnya teks-teks yang berhuruf Latin dengan bahasa Bali dan Indonesia menjadikan masyarakat Bali semakin malas membaca teks-teks akar kebudayaan nenek moyangnya, yakni teks-teks beraksara Bali. Pilihan teks berbahasa Latin seakan-akan memperparah posisi tawar aksara Bali sebagai dokumen pencatat warisan leluhur Bali untuk diminati oleh penuturnya.

Maksud dari pidato Poerbatjaraka untuk menyelamatkan "...peti tempat penjimpanan sastra dan budaja lama" di atas kandas oleh kebijakan dan sikap masyakat Bali sendiri yang hanya memikirkan salah satu unsur kebudayaan Bali, yakni bidang kesenian saja. Membanjirnya kunjungan wisatawan manca negara ke Bali sejak tahun 1970-an hingga 1990-an meninabobokkan komponen masyarakat Bali hingga lupa dengan akar budayanya. Yang miris lagi, salah satu acara "SARASEHAN" dalam Pesta Kesenian Bali yang diadakan sejak tahun 1979 itu seakan ikut memperparah posisi tawar teks Bali yang beraksara Bali itu bagi penerusnya. Dalam konsep awalnya, acara Sarasehan tersebut dimaksudkan agar para pembicara diarahkan untuk mengupas isi teks-teks Bali yang beraksara Bali yang jumlahnya segudang itu kemudian digunakan sebagai pengayaan materi PKB sepanjang tahun! Namun, dalam pelaksanaannya, setakat ini, dibumbui dengan telaah fenomena kekinian dengan ilmu-ilmu modern sebagai pisau bedahnya.

Bentuk-bentuk aktivitas di luar membaca teks-teks berhuruf Bali bagi masyarakat Bali ke depan tentu merupakan kemerosotan laku budaya bagi penerus budaya Bali. Untuk itu, usaha menyelamatkan kebudayaan Bali penting dimulai dari membumikan aksara Bali bagi masyarakat Bali dan penguasaan bahasa yang tersurat dalam lontar (Bali Tengahan, Jawa Kuna, dan Sanskerta) mutlak dimasukkan ke dalam kurikulum pembelajaran pada pendidikan formal dan nonformal sejak dini di Bali!

\section{Titik Balik Peradaban: Memaknai Pesan Pendiri Fakultas Ilmu Budaya Unud}

Bila berpijak dari tahun 1970-an sebagai tonggak 'peminggiran' atau 'krisis' aksara Bali dalam ranah pendidikan dan kehidupan masyarakat Bali maka Bali telah tercerabut dari akar budayanya sekitar 49 tahun. Kekeliruan kita dalam memaknai pesan moral dari pendiri FIB itu hendaknya jangan sampai berlarut-larut. Fritjop Capra memberikan pandangan bahwa memaknai krisis dalam konteks pemaknaan arti pentingnya pembelajaran aksara Bali bagi masyarakat Bali penting ditiru model yang digunakan masyarakat Cina. Menurut Capra (2014:10) istilah yang mereka gunakan untuk 'krisis' -wei-ji- yang bermakna "bahaya" dan "kesempatan".

Dalam konteks Bali, kesempatan untuk membalikkan keadaan dari 'krisis' di bidang pemanfaatan aksara Bali dalam arti luas bagi suku Bali adalah adanya momentum yang tepat untuk menggerakkan komponen masyarakat Bali. Menggerakkan hasrat cinta terhadap aksara Bali, mampu membaca dengan fasih, serta mempunyai minat baca-tulis dengan huruf Bali secara intens dan masif adalah kewajiban komponen masyarakat Bali saat ini dan ke depan. Momentum untuk memaknai pesan dari pendiri Fakultas Sastra Udayana (Fakultas Ilmu Budaya saat ini) tampaknya, tahun 2016 yang lalu sebagai tonggak awal! Dikatakan demikian, ada beberapa fakta yang perlu diungkap yang dilakukan oleh komponen masyarakat Bali dalam mendukung harapan dimaksud di atas.

Wacana pelestarian akar kebudayaan Bali berupa aksara Bali sebetulnya sudah dilakukan 
sejak lama, setidak-tidaknya upaya pendirian Pusat Dokumentasi Lontar di Dinas kebudayaan Provinsi Bali adalah salah satu upaya selain upaya lainnya yang dilakukan oleh lembaga maupun perseorangan. Badan Bahasa, Aksara dan Sastra Bali Provinsi Bali pun di tahun 1992 dibentuk yang diperkuat dengan Keputusan Gubernur Kepala Daerah Tingkat I Bali dan tercatat dalam Lembaran Daerah Propinsi Daerah Tingkat I Bali Peran Nomor: 384 Tahun 1992 Seri: D No.378. (Biro Humas Setwilda Tingkat I Bali, 1992: 122 - 134). Belakangan, tahun 2013 sejak gonjangganjingnya penerapan Kurikulum 2013 bagi dunia pendidikan dasar sampai menengah atas/Madrasah Aliyah (MA) yang mengintegrasikan pendidikan bahasa daerah ke dalam mata pelajaran kesenian, Gubernur Bali menerbitkan Peraturan Gubernur Bali Nomor 20 Tahun 2013 tentang Bahasa, Aksara dan Sastra Daerah Bali pada Pendidikan Dasar dan Menengah. Usaha di atas tidak serta merta membuat komponen masyarakat Bali berpihak pada akar peradabannya, yakni mau menyadari pentingnya untuk kembali kepada aksara Bali. Lebih-lebih peraturan Gubernur Bali itu diterangai dari klausulnya tidak memihak kepada guru bahasa Bali (khususnya kegamangan dalam menyediakan perangkat aturan yang menyediakan guru bahasa Bali bagi dunia pembelajaran di Bali) (Lihat Bali Post Minggu Kliwon, 31 Mei 2015 hlm.1 dan hlm 23). Dukungan yang melegakan berupa regulasi dikeluarkan oleh Gubernur Bali berupa Perda Nomor 1 Tahun 2018 tentang Bahasa, Aksara, dan Sastra Bali dan Pergub Bali Nomor 80 Tahun 2018 tentang Pelindungan dan Penggunaan Bahasa, Aksara, dan Sastra Bali serta Penyelenggaraan Bulan Bahasa Bali.

Gerakan sporadis untuk mendukung usaha-usaha penyelamatan budaya Bali dilakukan oleh tenaga kontrak Penyuluh Bahasa Bali yang direkrut pertengahan tahun 2016 silam. Adapun jumlah mereka yang direkrut oleh Pemda Bali lewat Dinas Kebudayaan Provinsi Bali sebanyak 716 orang yang ditempatkan di masing-masing Desa Dinas di seluruh Bali sejak bulan Juli 2016 yang lalu. Usaha mereka yang mampu menggerakkan perhatian penentu kebijakan di Bali untuk ditindaklanjuti adalah pendataan lontar yang ada di masyarakat. Dari hasil pendataan Penyuluh Bahasa Bali itu terdata 8.000 cakep (satu buah lontar dalam satu judul) lontar yang tidak terawat milik masyarakat. Dari jumlah tersebut 2.000 cakep dalam keadaan rusak dan hanya 6.000 cakep yang masih utuh. Gaung usaha-usaha pendataan lontar yang mereka lakukan di seluruh Bali dengan cepat direspons oleh penentu kebijakan di Bali. Buktinya, wacana pengangkatan guru-guru bahasa Bali telah muncul di media masa yang dipelopori oleh Bupati Badung, kemudian Wali Kota Denpasar juga berencana mengangkat tenaga guru bahasa Bali. Pada hari Minggu, 11 Desember 2016 yang lalu diadakan acara Festival Nyastra, yaitu menulis aksara Bali massal di seluruh Bali yang diprakarsai oleh Penyuluh Bahasa Bali dan mampu mendatangkan peserta sebanyak 7.387 orang anak-anak SD kelas-4 sampai kelas-6. Adapun rinciannya sebagai berikut. Kabupaten Buleleng diikuti sebanyak 1.310, Jembrana 460 orang, Tabanan 635 orang, Badung 1.220 peserta, Denpasar 689 orang, Gianyar 560 peserta, Klungkung 1.013 peserta, Bangli 1.000 orang, Karangasem sebanyak 500 orang peserta.

Selanjutnya, dalam konteks FIB sebagai pemegang mandat seperti petikan pidato di atas mestinya teks-teks yang tersimpan rapi di UPT Perpustakaan Lontar diberdayakan. Lebih-lebih Prodi Sastra Bali dan Jawa Kuna mesti diberikan keleluasaan untuk menyusun silabusnya agar menyelaraskan mata kuliah yang ada supaya mempunyai tautan dengan teks-teks lontar yang ada di perpustakaan lontar milik Udayana tersebut. Mengkontekskan isi lontar dengan kebutuhan masyarakat Bali secara lokal dan masyarakat dunia secara mengglobal bagi kedua prodi tersebut penting dilakukan agar FIB tidak dikatakan ingkat terhadap pesan kedua tokoh penting pendiri Perguruan Tinggi Negeri pertama yang ada di Bali tercinta ini.

\section{Simpulan}

Pesan moral yang disampaikan oleh Bung Karno dan Poerbatjaraka dalam pembukaan Fakultas Sastra Udayana tanggal 29 September 1958 adalah, dengan berdirinya perguruan tinggi negeri satu-satunya di Pulau Dewata ini diharapkan agar mampu mempertahankan, melestarikan, dan mengembangkan kebudayaan Bali. Kebudayaan Bali tersebut tersimpan dalam alas tulis (writing material) berupa lontar dengan bahasa Bali, Jawa Kuna, dan bahasa Sanskerta sebagai wahana pengungkapannya.

Dalam perkembangannya, Fakultas Sastra yang sekarang telah berubah nama dua kali (Fakultas Sastra dan Budaya) dan sekarang 
(Fakultas Ilmu Budaya) belum mampu menjawab harapan dari presiden RI pertama dan Dekan pertama Fakultas Sastra. Tampaknya ada kesalahan kurikulum di masing-masing Prodi yang ada di lingkungan FIB sehingga tantangan dan peluang dalam menjawab harapan pendiri Fakultas Sastra dahulu tidak mampu dipenuhi, meskipun usianya sudah menjelang 61 tahun.

Tonggak baru bagi pemenuhan harapan pendiri Fakultas Sastra Udayana agar "kunci wasiat" untuk membuka peti penyimpan khazanah budaya Bali yang tersurat dalam daun lontar dengan aksara Bali itu tampaknya dimulai tahun 2016 silam. Perhatian penentu kebijakan di Bali mulai tampak dalam memberdayakan SDM Bali yang berkecimpung dalam dunia bahasa, aksara, dan sastra Bali dengan mengangkat tenaga Penyuluh Bahasa Bali sejak 2016. Demikian pula dengan kebijakan Bupati/Walikota di Bali yang telah mewacanakan akan mengangkat tenaga guru bahasa Bali, merupakan awal mula yang baik untuk memperhatikan budaya Bali dalam arti luas. Selain itu, regulasi berupa undang-undang telah dikeluarkan oleh Gubernur Bali berupa Perda Nomor 1 Tahun 2018 tentang Bahasa, Aksara, dan Sastra Bali dan Pergub Bali Nomor 80 Tahun 2018 tentang Pelindungan dan Penggunaan Bahasa, Aksara, dan Sastra Bali serta Penyelenggaraan Bulan Bahasa Bali. Meskipun, di sisi yang lain, pembelajaran aksara Bali masih belum menemukan formula yang tepat.

\section{Daftar Pustaka}

Atmaja, Jiwa. 2014. "Membaca Ulang Pola Ilmiah Pokok Kebudayaan" dalam Wahana Media Pematang Alumni Udayana. Edisi No. 87 TH.XXX Mei 2014.

Bali Post edisi Selasa Paing, 6 Oktober 2009 hal. 2 "Rektor Unud Prof. Bakta Tugas Berat Menuju "World Class University".
Bali Post Minggu Kliwon, 31 Mei 2015 hlm.1 dan hlm 23. "Pergub Tak Bela Guru Bahasa Bali".

Capra, Fritjop. 2014. Titik Balik Peradaban: Sains, Masyarakat, dan Kebangkitan Kebudayaan. Diindonesiakan dari judul aslinya "The Turning Point Science, Society and The Rising Culture" oleh M. Thoyibi (UMS). Yogyakarta: Pustaka Promethea.

Suardiana, I Wayan. 2009. "Merumuskan Ajeg Bali Berdasarkan Teks" dalam Wahana Media Pematang Alumni Udayana. Edisi No. 67 TH.XXV November 2009.

Suardiana, I Wayan. 2015. "Peran Fakultas Sastra dan Budaya Universitas Udayana dalam Memaknai Pola Ilmiah Pokok (PIP) Kebudayaan Bagi UNUD" dalam Wahana Media Pematang Alumni Udayana Edisi No.93 TH.XXXI Nopember 2015.

Suardiana, I Wayan. 2016. "Teks Lontar sebagai Landasan Memperkuat Pola Ilmiah Pokok (PIP) Kebudayaan di Masing-masing Fakultas di Lingkungan Universitas Udayana" Paper dalam Diskusi Kelompok Terarah (FGD) tentang Pustaka Lontar dan PIP Kebudayaan Unud dalam Rangka Dies Unud ke-54 di FIB Unud.

Teeuw. A. 1983. Membaca dan Menilai Sastra. Jakarta: Penerbit PT Gramedia.

Tim Penyusun. 1983. Statuta universitas Udayana. Denpasar: Universitas Udayana.

Zoetmulder, P.J. 1985. Kalangwan Sastra Jawa Kuno Selayang Pandang. Diindonesiakan dari judul aslinya KALANGWAN. A Survey of Old Javanese Literature oleh Dick Hartoko SJ. Jakarta: Djambatan. 